\title{
Review Article \\ Bio-Inspired Optimization of Sustainable Energy Systems: A Review
}

\author{
Yu-Jun Zheng, ${ }^{1}$ Sheng-Yong Chen, ${ }^{1}$ Yao Lin, ${ }^{2}$ and Wan-Liang Wang' \\ ${ }^{1}$ College of Computer Science \& Technology, Zhejiang University of Technology, Hangzhou 310023, China \\ ${ }^{2}$ College of Life Sciences, Fujian Normal University, Fuzhou, Fujian 350108, China \\ Correspondence should be addressed to Sheng-Yong Chen; sy@ieee.org
}

Received 12 December 2012; Accepted 17 January 2013

Academic Editor: Maurizio Carlini

Copyright (c) 2013 Yu-Jun Zheng et al. This is an open access article distributed under the Creative Commons Attribution License, which permits unrestricted use, distribution, and reproduction in any medium, provided the original work is properly cited.

\begin{abstract}
Sustainable energy development always involves complex optimization problems of design, planning, and control, which are often computationally difficult for conventional optimization methods. Fortunately, the continuous advances in artificial intelligence have resulted in an increasing number of heuristic optimization methods for effectively handling those complicated problems. Particularly, algorithms that are inspired by the principles of natural biological evolution and/or collective behavior of social colonies have shown a promising performance and are becoming more and more popular nowadays. In this paper we summarize the recent advances in bio-inspired optimization methods, including artificial neural networks, evolutionary algorithms, swarm intelligence, and their hybridizations, which are applied to the field of sustainable energy development. Literature reviewed in this paper shows the current state of the art and discusses the potential future research trends.
\end{abstract}

\section{Introduction}

The demand for energy supply is increasing rapidly in recent years and will probably continue to grow in the future. The realization that fossil fuel resources are becoming scarce and that climate change is related to carbon emissions has stimulated interest in sustainable energy development [1]. In general, sustainable energy development strategies involve three major technological changes: energy savings on the demand side, efficiency improvements in the energy production, and replacement of fossil fuels by various sources of renewable energy [2]. In particular, due to its multifold advantages including inexhaustibility, safety, decrease in external energy dependence, decrease in impact of electricity production and transformation, increase in the level of services for the rural population, and so forth [3], renewable energy is now considered an important resource around the world and regarded as a key component in obtaining a sustainable development of our society.

The implementation of sustainable energy development strategies involves a wide range of design, planning, and control optimization problems. Various conventional optimization methods, such as linear programming [4-6], integer programming $[7,8]$, mixed integer linear programming [912], nonlinear programming [13-16], dynamic programming (DP) [17-20], constrained programming [21, 22], and so forth, have been applied for solving these problems. Nevertheless, current optimization problems in sustainable energy systems become more and more complex, especially when they include the integration of renewable sources in coherent energy systems. This is because most of such problems are nonlinear, nonconvex, with multiple local optima, and included in the category of NP-hard problems [23]. In consequence, those conventional methods might need exponential computation time in the worst case to obtain the optimum, which leads to computation time that is too high for practical purposes [24]. In recent years, modern heuristic optimization techniques, which are stochastic search methods inspired by the concepts and principles of artificial intelligence, have gained popularity in the optimization of sustainable energy systems.

In this paper, we give an overview of the latest research advances in bio-inspired solution methods for sustainable energy development. We particularly focus on the bioinspired optimization algorithms that have been applied to the design, planning, and control problems in the field of 
renewable and sustainable energy systems. We roughly group those methods into three categories, which are artificial neural networks (ANNs), evolutionary algorithms (EAs), and swarm intelligence. Besides, we also describe the recent work about the hybridization of individual methods. These heuristic methods usually do not require deep mathematical knowledge and have been demonstrated to be quite useful and efficient in optimization search for complex optimization problems in science and engineering. We believe that this paper can help researchers to gain knowledge about the major developments emerged throughout the years and find valuable approaches that can be applied in the practice of implementing sustainable energy systems.

The rest of the paper is synthesized as follows: Section 2 reviews the application of ANNs in sustainable energy development, Section 3 summarizes the work about EAs applied to different types of optimization problems in energy, Section 4 presents the recent advances in swarm-based methods used in the field, Section 5 introduces the hybrid techniques combining two or more of above methods, and Section 6 concludes with discussion.

\section{Artificial Neural Networks}

An ANN is a collection of neuron-like processing units with weighted connections between the units, which is inspired by our present understanding of biological nervous systems. Roughly speaking, ANNs use processing elements connected by links of variable weights to form a black box representation of systems [25]. ANNs can be trained by adjusting the weights so as to be able to predict or classify new patterns, and they provide some of the human characteristics of problem solving that are difficult to simulate using other computational technologies. Advantages of ANN include their high tolerance of noisy data, their ability to process patterns on which they have not been trained, as well as that they can be used without much preliminary knowledge about the problem domain. However, ANNs typically involve long training times and have been criticized for their poor interpretability [26].

ANNs are popular for prediction and forecasting nonlinear physical series (such as wind [27] and water lever [28]) which are beyond the capability of linear predictors such as autoregressive (AR), moving average (MA), and autoregressive moving average (ARMA), [29-31]. Since 1990s, various studies have been reported on the applications of ANN in predicting electric loads and energy demands. An early work of Kawashima [32] developed an ANN backpropagation model with three-phase annealing for the first building energy prediction competition held by the American Society of Heating, Refrigerating- and Air-Conditioning Engineers in 1993. Islam et al. [33] proposed an ANN-based weatherload and weather-energy models, where a set of weather and other variables are identified for both models together with their correlations and contribution to the forecasted variables. They applied the models to historical energy, load, and weather data available for the Muscat power system from 1986 to 1990, and the forecast results for 1991-1992 show that monthly electric energy and load can be predicted within a maximum error of $6 \%$ and $10 \%$. Al-Shehri [34] used an ANN model for forecasting the residential electrical energy in the Eastern Province of Saudi Arabia, the forecasting result of which is shown to be closer to the real data than that predicted by the polynomial fit model. Azadeh et al. [35] developed a simulated-based ANN and applied it in forecasting monthly electrical energy consumption in Iran from March 1994 to February 2005 (131 months), and the result shows that the ANN model always provides the best solutions and estimation in comparison with other models such as time series.

ANNs have also been applied in midterm and long-term energy forecasting in different industrial sectors, areas, and countries and demonstrated their superiorities in comparison with conventional prediction models [36-41]. In [42] Ermis et al. presented an ANN model which is trained based on world energy consumption data from 1965 to 2004 and applied for forecasting world green energy consumption to the year 2050. It is estimated that world green energy and natural gas consumption will continue increasing after 2050, while world oil and coal consumption are expected to remain relatively stable after 2025 and 2045, respectively.

In recent years, ANN-based models have also been widely used in design and implementation of different kinds of renewable energy systems. For example, in the design of solar energy systems the estimation and calculation of radiation data are very important. Bosch et al. [43] presented an ANN approach for calculating solar radiation levels over complex mountain terrains using data from only one radiometric station. Cao and Lin [44] proposed a diagonal recurrent wavelet neural network which uses historical information of cloud cover to sample data sets for network training and applied their approach in hourly irradiance forecasting in Shanghai, China. Zervas et al. [45] developed an ANNbased prediction model of global solar irradiance distribution on horizontal surfaces, which has been applied to the meteorological database of NTUA, Zografou Campus, Athens.

In the same manner, the prediction of water level is fundamental for ocean energy generation. Huang et al. [46] developed an ANN for water level predictions, which has been applied to coastal inlets taking into account long-term water level observations. Kazeminezhad et al. [47] studied an ANN-based fuzzy inference system for predicting wave parameters, with an application to the data set comprising of fetch-limited wave data and over water wind data gathered from deep-water location in Lake Ontario.

The performance of photovoltaic system heavily depends on the meteorological conditions, and sizing represents an important part of photovoltaic systems design, that is, the optimal selection of the number of solar, cell panels, the size of the storage battery, and the size of wind generator to be used for certain hybrid applications [48]. ANNs have the capability to model complex, nonlinear processes without having to assume the form of the relationship between input and output variables, and thus ANN-based models, including adaptive ANN [49, 50], recurrent ANN [51], radial basis function network (RBFN) [52], have been successfully applied for sizing of photovoltaic systems. 


\section{Evolutionary Algorithms}

Evolutionary algorithms (EAs) are stochastic search methods inspired by the principles of natural biological evolution for computationally difficult problems. They are very suitable for complex engineering optimization problems which may be multimodal, nondifferentiable, or discontinuous and thus cannot be solved by conventional gradient-based methods. In general, An EA simultaneously evolves a population of possible solutions and also returns a population of solutions. Typical EAs include genetic algorithms (GAs) [53], evolutionary programming (EP) [54], evolution strategies (ES) [55], differential evolution (DE) [56], and biogeography-based optimization (BBO) [57]. The advantages of EAs include their relative simplicity of implementation, inherent parallel architecture, and scalability to high-dimensional solution spaces.

Moreover, in real-world applications there are a large number of multiobjective optimization problems, that is, problems requiring the simultaneous optimization of several objectives which are often conflicted. For most of such problems, there is no single optimal solution and thus a solution method should search for a set of nondominated (Pareto optimal) solutions, that is, all the solutions such that there exists no other individual better in all the objectives. EAs are capable of finding several members of the Pareto optimal set in a single run of the algorithm, instead of having to perform a series of separate runs as in the case of the traditional mathematical programming techniques [58] and thus are very suitable for tackling with complex multiobjective optimization problems.

3.1. Genetic Algorithms. Genetic algorithms (GAs) are of the famous evolutionary algorithms which simulate the Darwinian principle of natural selection and the survival of the fittest in optimization [53]. A GA typically works with a fixedsize population of solutions and uses three genetic operations, namely selection, crossover, and mutation, to modify the solutions chosen from the current generation and select the most appropriate offspring to pass on to the next generations.

A number of researches have been reported on the application of GA in the optimal design and operation of sustainable energy systems. For wind energy systems, Li et al. [59] used a multilevel GA to solve the optimal design problem of integrating the number of actuators, the configuration of the actuators, and the active control algorithms in buildings excited by strong wind force. Li et al. [60] employed a GA to optimize the ranges of gearbox ratios and power ratings of multihybrid permanent-magnet wind generator systems. Grady et al. [61] used a GA to determine the optimal placement of wind turbines for maximum production capacity while limiting the number of turbines installed and the acreage of land occupied by each wind farm. Emami and Noghreh [62] proposed a GA with a new coding and a new objective function with adjustable coefficients for the similar problem, and their algorithm shows better performance on the optimal control of the cost, power, and efficiency of the wind farm. For solar energy systems, Varun and Siddhartha [63] proposed a GA to optimize system parameters in order to maximize the thermal performance of flat plate solar air heaters. Zagrouba et al. [64] adapted a GA to identify the electrical parameters of photovoltaic solar cells and modules to determine the maximum power point from the illuminated current-voltage characteristic. GAs have also been used in geothermal systems [65] and hybrid photovoltaic systems [66-70].

3.2. Evolutionary Programming and Evolution Strategies. Evolutionary Programming (EP) was devised in order to evolve finite state machines for the prediction of events on the basis of former observations and has been demonstrated useful for searching the optimum of nonlinear functions [71]. Cau and Kaye [72] proposed a constructive EP approach to minimize the cost of operating a power system with multiple distributed energy storage resources. Their approach combines DP and EP by evolving piecewise linear convex cost-to-go functions and thus decomposes the multistage scheduling problem into smaller one-stage sub-problems which are easy to cope with. Fong et al. [73] developed a simulation-EP coupling method to solve the discrete, nonlinear, and highly constrained optimization problems related to energy management of heating, ventilating, and air-conditioning (HVAC) systems. The application of the method to a local HVAC installation project achieved a saving potential of about $7 \%$ as compared to the existing operational settings, without any extra cost. In [74] MacGill presented a dual EP approach integrating with software agents for power system resources to coevolve optimal operational behaviors over repeated power system simulations. The proposed tool was successfully applied to a real-world problem exploring the potential operational synergies between significant PV penetrations and distributed energy storage options including controllable loads.

Evolution strategies (ES) are a class of general optimization methods which evolve a population of solutions by means of variation and selection. Original ES uses a mutation operator that produces a single descendent from a given ancestor, denominated ES- $(1+1)$, and was progressively generalized to ES- $(\mu+\lambda)$, that is, several ancestors $(\mu>1)$ and descendents $(\lambda>1)$ in each generation [75]. In [76] Chang used an ES approach to solve optimal chiller loading problem, which takes the chilled water supply temperature as the variable to be determined for the decoupled air-conditioning system. The result shows, the approach outperforms both the Lagrangian method and the GA method. Considering the optimal selection and sizing of distributed energy resources which can be formulated as a nonlinear mixed-integer minimization problem, Logenthiran et al. [77] used ES for the minimization of capital and annual operational cost of DER under a variety of system and unit constraints. Their method was applied to design integrated microgrids for an intelligent energy distribution system project.

3.3. Differential Evolution. Differential evolution (DE) approach combines simple arithmetic operators with the classical operators of crossover, mutation, and selection to evolve a randomly generated starting population to a final solution. It is similar to a $(\mu+\lambda)$ ES, but in DE 
the mutation is not done via some separately defined probability density function [78]. Chakraborty et al. [79] presented a fuzzy DE method for solving thermal unit commitment problem integrated with solar energy system, where the solar radiation, forecasted load demand and associated constraints are formulated as fuzzy sets considering the error. Slimani and Bouktir [80] developed a DE method to solve the optimal power flow problem, whose objective function is the minimization of the cost of the thermal and the wind generators with different sizes. The method decomposes the optimization constraints of the power system into active constraints manipulated directly by $\mathrm{DE}$, and passive constraints maintained in their soft limits using a conventional constraint load flow.

dos Santos Coelho et al. [81] developed a cultural DE algorithm for optimizing the economic dispatch of electrical energy using thermal generators and validated their approach on a test system consisting of 13 thermal generators whose nonsmooth fuel cost function takes into account the valvepoint loading effects. Suzuki et al. [82] studied a large-scale mixed-integer nonlinear problem for generating optimal operational planning for energy plants and developed an $\varepsilon$ constrained DE algorithm to effectively solve the problem without much parameters tuning effort. Hejazi et al. [83] developed a DE algorithm for optimal allocation of energy and spinning reserve, taking all security and power systems constraints in steady state and system credible contingencies into consideration. Lee et al. [84] conducted a comparative study of DE, GA, PSO, and LP methods for solving the optimal chiller loading problem for reducing energy consumption, and the result shows that the DE algorithm achieves the best result. Peng et al. [85] considered a problem in the design of the Earth-Moon low-energy transfer to find the patch point of the unstable manifold of the Lyapunov orbit around Sun-Earth L2 and the stable manifold of the Lyapunov orbit around Earth-Moon L2. They designed an improved differential evolution algorithm which incorporates the uniform design technology and the self-adaptive parameter control method into standard differential evolution to accelerate its convergence speed and improve the stability, and thus effectively solve the problem.

3.4. Multiobjective Evolutionary Algorithms. Multiobjective evolutionary algorithms (MOEAs) have received much interest in recent years. A number of metaheuristic algorithms, such as the nondominated sorting genetic algorithm NSGA [86] and the NSGA-II [87], the strength Pareto evolutionary algorithm (SPEA) [88] and the SPEA2 [89], the Pareto archived evolution strategy (PAES) [90], the Pareto differential evolution algorithm (PDE) [91], the nondominated sorting differential evolution (NSDE) [92], and so forth have gained great success in solving multiobjective optimization problems [93].

Benini and Toffolo [94] presented an MOEA for the design of stall-regulated horizontal-axis wind turbines, the aim of which is to achieve the best trade-off performance between the total energy production per square meter of wind park and cost. Their method can optimize the geometrical parameters of the rotor configuration of wind turbines, achieving the best trade-off performance between the two objectives. Zhao et al. [95] employed a GA whose input parameters are the main components of a wind farm and key technical specifications and whose output is an optimal electrical system design of the wind farm which is optimized in terms of both production cost and system reliability. Kusiak et al. [96] proposed an MOEA for evaluating wind turbine performance, where the objectives include the maximization of the wind power output and the minimization of the vibration of the drive train and of the tower. In [97] Kusiak and Song used the MOEA for optimizing wind turbine placement based on wind distribution, including the selection the best turbine combination from a given list of available turbines.

Bernal-Agustín et al. [98] applied the SPEA to the design of a photovoltaic-wind-diesel system, where the objectives include the minimization of both the total cost throughout the useful life of the installation and the pollutant emissions. They later applied the algorithm to an extension of the problem, which adds an objective of the unmet load in the system [99]. Ould Bilal [100] proposed a multiobjective GA for minimizing the annualized cost system and the loss of power supply probability of a hybrid solar-wind-battery system. Montoya et al. [101] combined PAES with simulated annealing (SA) and tabu search (TS) to minimize voltage deviations and power losses in power networks. Thiaux et al. [102] applied NSGA-II to optimize stand-alone photovoltaic systems by reducing the gross energy requirement and minimizing the storage capacity. In [103] Rao and Peng considered a multiobjective optimal model of dispatch of energy-saving and emission reduction generation in the power system and developed a multiobjective DE algorithm with niche strategy for improving the crowing mechanism in the process of Pareto nondominated sorting operation. The experiment shows that their method can achieve better result than NSGAII and NSDE.

\section{Swarm Intelligence}

The expression "swarm intelligence" was originally used in the context of cellular robotic systems to describe the selforganization of simple mechanical agents through nearestneighbor interaction [104]. Bonabeau et al. [105] extended the definition to include "any attempt to design algorithms or distributed problem-solving devices inspired by the collective behavior of social insect colonies and other animal societies." Since the 1990s, a number of swarm-based algorithms, including particle swarm optimization (PSO) [106], ant colony optimization (ACO) [107], artificial bee algorithms [108, 109], artificial immune systems (AIS) [110] have been proposed for difficult optimization problems especially with large continuous or combinatorial search spaces.

4.1. Particle Swarm Optimization. PSO is another population-based global optimization technique that enables a number of individual solutions, called particles, to move through a hyperdimensional search space to search for the optimum. Each particle has a position vector and a velocity vector, which are adjusted at iterations by learning from a local best found by the particle itself and a current global 
best found by the whole swarm. Empirical studies have shown that PSO has a high efficiency in convergence to desirable optima and performs better than GA and other EAs on many problems [111].

AlRashidi and EL-Naggar [112] employed a PSO algorithm for estimating annual peak load forecasting in an electrical power system, the aim of which is to minimize the error associated with the estimated model parameters. Their approach was validated on actual recorded data from Kuwaiti and Egyptian networks. Niknam and Firouzi [113] developed a PSO algorithm combined with simplex search, for estimating load and renewable energy source output on the power systems, and their comparative experiment show that the PSO performs better than several EAs and other swarm-based algorithms.

Amjady and Soleymanpour [114] developed a modified adaptive PSO for daily hydrothermal generation scheduling, which is a complicated nonlinear, nonconvex, and nonsmooth optimization problem with discontinuous solution space. As some other adaptive PSOs $[115,116]$, their method dynamically changes the inertia weight and acceleration coefficients of the algorithm to increase activities of particles to explore broad space. Lee [117] applied PSO to solve short-term hydroelectric generation scheduling of a power system with wind turbine generators. Kongnam and Nuchprayoon [118] used PSO for the control problem of a wind turbine, which involves the determination of rotor speed and tip-speed ratio to maximize power and energy capture from the wind. Khanmohammadi et al. [119] developed a method based on PSO and Nelder-Mead algorithms for determining the optimal unit commitment (startups and shutdowns scheduling) of hydropower plants. López et al. [120] presented a binary PSO-based method to accomplish optimal location of biomass-fuelled systems for distributed power generation with forest residues as biomass source, and the results outperformed those obtained by a GA when maximizing a profitability index taking into account technical constraints. In [121] the authors also applied a PSO algorithm for the optimal location and supply area for biomass-based power plants. There are also a number of researches reported on the application of PSO in the design and control of hybrid photovoltaic systems [122126].

Economic dispatch problems, the main aim of which is to schedule the committed generating units output so as to meet the required load demand at minimum cost satisfying all unit and system operational constraints, typically have nonlinear, nonconvex type objective function with intense equality and inequality constraints. Mahor et al. [127] presented a yearly (2003-2008) review of work of application of PSO to solve the various economic dispatch problems. The algorithms include linearly varying inertia weight PSO $[128,129]$, PSO with constriction factor and inertia weight $[130,131]$, PSO with linearly varying inertia weight with constriction factor [132], chaotic PSO [133-135], and multiobjective PSO [136-139]. It was suggested that PSO algorithms (in particular those with time varying control parameters) can give an improved results within less computational time in comparison to conventional methods, but still further improvements in PSO algorithms are required, especially for real-time scheduling problems.

4.2. Ant Colony Optimization. Ant colony optimization (ACO) algorithms mimic the behavior of real ants living in colonies that communicate with each other using pheromones in order to accomplish complex tasks such as establishing a shortest path from the nest to food sources [107]. Li et al. [140] applied an ACO algorithm to the optimal design of solar energy dynamic power system in space station, with the aim to minimize the launching mass of the system subject to a set of constraints on parameters including pressure, temperature, compression coefficient, numbers and diameter of heat exchangers, height of recycling refrigerant, and so forth. Considering the optimal sizing of the design of standalone hybrid wind/photovoltaic power systems, Xu et al. [141] used ACO to minimize the total capital cost, subject to the constraint of the loss of power supply probability calculated by simulation. Foong et al. [142] considered a power plant maintenance scheduling optimization formulation incorporating the options of shortening the maintenance duration and/or deferring maintenance tasks in the search for practical maintenance schedules and developed an improve ACO algorithm for solving the problem. Warner and Vogel [143] considered planning of an energy supply network by simultaneously choosing the plants and the optimal network and implemented an ACO algorithm for the problem. See et al. [144] used ACO for determining optimal parameter values to the control model of energy extraction and thus improving the performance of wave energy converters as well as their long-term economic value.

Toksari [145] proposed an ACO electricity energy estimation model for forecasting electricity energy generation and demand, taking population, gross domestic product (GDP), import and export into consideration. He found that the model with quadratic equations can provide better fit solution due to the fluctuations of the economic indicators. The proposed model was applied to indicate Turkey's net electricity energy generation and demand until 2025. Baskan et al. [146] used ACO for estimating the transport energy demand of Turkey using gross domestic product, population, and vehicle-km. It is also expected that the work will be helpful in developing highly applicable and productive planning for transport energy policies.

4.3. Artificial Bee Algorithms. Artificial bee algorithms simulate the intelligent foraging behavior of a honeybee swarm. Two most popular algorithms are the artificial bee colony $(\mathrm{ABC})$ algorithm and the honey bee mating optimization (HBMO) algorithm [147]. Niknam et al. [148] presented a multiobjective HBMO algorithm for the siting and sizing of renewable electricity generators, in order to optimize the placement of renewable electricity generators by considering objective functions including losses, costs of electrical generation, and voltage deviation. In [149] Niknam et al. also proposed an improve a HBMO algorithm for economic dispatch in power systems, with the aim to get maximum usable power using minimum resources. Abu-Mouti and El-Hawary [150] considered a dynamic economic dispatch problem, whose 
aim is to determine the optimal power outputs of online generating units in order to meet the load demand subject to satisfying various operational constraints over finite dispatch periods, and they applied an ABC algorithm to solve the problem.

Vera et al. [151] proposed a binary honey bee foraging (HBF) swarm approach for searching the optimal location, biomass supply area, and power plant size that offer the best profitability for investor. Experimental results show that the HBF approach method outperforms PSO and GA. Hong [152] presented an electric load forecasting model based on a chaotic $\mathrm{ABC}$ algorithm combined with the seasonal recurrent support vector regression model, and the experiments indicated that the model can provide a promising forecasting performance for electric load.

4.4. Artificial Immune System (AIS). Inspired by the theoretical immunology, observed immune functions, principles, and models, AIS stimulates the adaptive immune system of a living creature to unravel the various complexities in realworld engineering optimization problems. Abdul Rahman et al. [153] developed an AIS algorithm for the economic dispatch problem, which uses the total generation cost as the objective function. Through genetic evolution, the antibodies with high affinity measure are produced and become the solution, and the algorithm converges within an acceptable execution time and highly optimal solution for economic dispatch with minimum generation cost. Coelho and Mariani [154] coped with the problem by using a chaotic artificial immune network approach, which has been demonstrated by the experiments to be an effective alternative to schedule the committed generating unit outputs to meet the required load demand at minimum operating cost while satisfying system constraints. Recently, Arsalani and Seddighizadeh [155] used an AIS algorithm to minimize the deviation of bus voltage from its nominal value as well as the loss of energy in a power system. The main advantage of the algorithm is that it prevents many times repetition of similar solutions, and the result shows that the algorithm can achieve a solution that meets a level of preferences better than that required although the threshold is determined by means of fuzzy logic to reflect the imprecise nature of optimization objectives.

\section{Hybrid Methods}

By exploiting the advantages and disadvantages of two or more solution methods, we have a chance to obtain a powerful approach that is much more competitive than any individual method. Research and development on hybrid bioinspired methods in sustainable energy systems have grown dramatically since the late 1990s.

Mellit and Kalogirou [156] studied the combination of GA and ANN for optimal sizing of stand-alone photovoltaic systems. Firstly the GA was used to optimize the sizing parameters of sites, and then the ANN was used to predict the optimal parameters in remote areas. Mellit later developed a hybrid model combining adaptive-network-based fuzzy inference system (ANFIS) and GA and demonstrated that the model with ANFIS presents more accurate results [157]. Chang and Ko [158] designed a hybrid heuristic method which combines PSO with nonlinear time-varying evolution and ANN in order to determine the tilt angle of photovoltaic modules with the aim of maximizing the electrical energy output of the modules.

Li et al. [159] proposed a method combining AIS and PSO, for optimal load distribution among cascade hydropower stations. Their hybrid method involves the immune information processing mechanism into PSO and thus improves the ability to find the globally excellent result and the convergence speed with its special concentration selection mechanism and immune vaccination. Yang et al. [160] combined GA and ABC into a bee evolutionary genetic algorithm (BEGA), which has characteristics of higher precision and faster convergence rate and has been effectively applied to a problem of minimizing the energy consumption of central air-conditioning system without lowering the degree of comfort. The test on a common load distribution case shows that the hybrid method can achieve an energy-saving rate at $25.1 \%$.

Kiran et al. [161] proposed a hybrid method of PSO and ACO for estimating energy demand, PSO for solving continuous optimization part and ACO for discrete part. The experiments demonstrated that the hybrid method outperforms both the individual PSO and ACO. In [162] Ghanbari et al. combined GA and ACO to model and simulate fluctuations of energy demand under the influence of related factors. Firstly the GA is used for generating data base of the expert system, and then the ACO is used for learning linguistic fuzzy rules such that degree of cooperation between data base and rule base increases. Results showed that the method can provide more accurate-stable results than ANFIS- and ANN-based approaches.

\section{Discussion and Conclusion}

We have summarized the recent research advances in bioinspired solutions applied to the design, control, and implementation of sustainable energy systems. Typical illustrations are addressed for ANNs, EAs, swarm-based algorithms, and their hybridizations. Representative works are summarized to help readers have a general overview of the state-of-the-art and easily refer suitable methods in practical solutions.

The first finding of this paper is that the number of research papers on bioinspired optimization algorithms on sustainable energy problems has increased dramatically since 1990s. A large percent of early work was GA related. However, in recent years, DE has become more popular in the category of EAs, and swarm-based methods have gained more and more attentions of the researchers and practitioners. In the last three years, we found that PSO algorithms have become one of the most widely used methods in the field of renewable and sustainable energy development.

In general, none of the individual methods could perform better than all the other methods on all kinds of problems, suggesting that customized methods need to be carefully chosen or designed according to the respective problem. But researchers and practitioners can learn from the experiences 
of early researchers. For example, on most problems of unit sizing of stand-alone hybrid energy systems, PSO typically outperforms GAs [163], mainly because PSO algorithms are more suitable for high-dimensional optimization problems, and improved versions of PSO are less sensitive to multiple local optima than GAs.

With the increasing importance and complexity of energy systems, we are facing the challenges to promote the performance, reliability, and scalability of solution methods [164, 165]. In consequence, it can be anticipated that future research will continuously put great emphasis on the hybridization of bio-inspired methods. In addition, more and more realworld problems in sustainable energy consider more than one objective. It can be expected that multiobjective bioinspired optimization algorithms and parallel processing will be promising research areas in this field [166]. Moreover, current studies on multiobjective algorithms combing more than one metaheuristics are still rare, and we think that this can be a valuable direction for the researchers.

Today's new computational paradigms, such as quantum computing [167], DNA computing [168], and fractal computing [169-172], provide valuable inspiration for creating new heuristics for extremely difficult problems. Thus, the extensions of current bio-inspired methods based on these new paradigms are expected to achieve dramatic improvement on computational performance. For example, quantum-inspired EAs are regarded as one of the three main research areas related to the complex interaction between quantum computing and EAs [173]. In the aspect of quantum computing, if applying ANNs, it is worth considering time series models in that aspect as that discussed by Bakhoum and Toma $[174,175]$. We believe that the fruits of these researches are continuously becoming new technological solutions to new open problems, and the full potential is far from being reached.

\section{Acknowledgments}

This work was supported by the National Natural Science Foundation of China (61105073, 61173096, and 61103140), Doctoral Fund of Ministry of Education of China (20113317110001), and Zhejiang Provincial Natural Science Foundation (R1110679).

\section{References}

[1] E. Vine, "Breaking down the silos: the integration of energy efficiency, renewable energy, demand response and climate change," Energy Efficiency, vol. 1, no. 1, pp. 49-63, 2008.

[2] H. Lund, "Renewable energy strategies for sustainable development," Energy, vol. 32, no. 6, pp. 912-919, 2007.

[3] A. Hepbasli, "A key review on exergetic analysis and assessment of renewable energy resources for a sustainable future," Renewable and Sustainable Energy Reviews, vol. 12, no. 3, pp. 593-661, 2008.

[4] R. Chedid and Y. Saliba, "Optimization and control of autonomous renewable energy systems," International Journal of Energy Research, vol. 20, no. 7, pp. 609-624, 1996.

[5] S. Iniyan and K. Sumathy, "The application of a Delphi technique in the linear programming optimization of future renewable energy options for India," Biomass and Bioenergy, vol. 24, no. 1, pp. 39-50, 2003.

[6] G. Privitera, A. R. Day, G. Dhesi, and D. Long, "Optimising the installation costs of renewable energy technologies in buildings: a linear programming approach," Energy and Buildings, vol. 43, no. 4, pp. 838-843, 2011.

[7] M. Gong, "Optimization of industrial energy systems by incorporating feedback loops into the MIND method," Energy, vol. 28, no. 15, pp. 1655-1669, 2003.

[8] P. Liu, D. I. Gerogiorgis, and E. N. Pistikopoulos, "Modeling and optimization of polygeneration energy systems," Catalysis Today, vol. 127, no. 1-4, pp. 347-359, 2007.

[9] T. Ikegami, Y. Iwafune, and K. Ogimoto, "Development of the optimum operation scheduling model of domestic electric appliances for the supply-demand adjustment in a power system," IEEJ Transactions on Power and Energy, vol. 130, no. 10, pp. 877-887, 2010.

[10] B. Wille-Haussmann, T. Erge, and C. Wittwer, "Decentralised optimisation of cogeneration in virtual power plants," Solar Energy, vol. 84, no. 4, pp. 604-611, 2010.

[11] H. Morais, P. Kádár, P. Faria, Z. A. Vale, and H. M. Khodr, "Optimal scheduling of a renewable micro-grid in an isolated load area using mixed-integer linear programming," Renewable Energy, vol. 35, no. 1, pp. 151-156, 2010.

[12] S. Ruangpattana, D. Klabjan, J. Arinez, and S. Biller, "Optimization of on-site renewable energy generation for industrial sites," in Proceedings of IEEE/PES Power Systems Conference and Exposition (PSCE '11), March 2011.

[13] C. A. Babu and S. Ashok, "Optimal utilization of renewable energy-based IPPs for industrial load management," Renewable Energy, vol. 34, no. 11, pp. 2455-2460, 2009.

[14] Z. Kravanja, "Mathematical programming approach to sustainable system synthesis," Chemical Engineering Transactions, vol. 21, pp. 481-486, 2010.

[15] A. Borghetti, M. Bosetti, S. Grillo et al., "Short-term scheduling and control of active distribution systems with high penetration of renewable resources," IEEE Systems Journal, vol. 4, no. 3, pp. 313-322, 2010.

[16] A. Vergnano, C. Thorstensson, B. Lennartson et al., "Modeling and optimization of energy consumption in cooperative multirobot systems," IEEE Transactions on Automation Science and Engineering, vol. 9, no. 2, pp. 423-428, 2012.

[17] E. D. Castronuovo and J. A. P. Lopes, "Optimal operation and hydro storage sizing of a wind-hydro power plant," International Journal of Electrical Power and Energy System, vol. 26, no. 10, pp. 771-778, 2004.

[18] N. Löhndorf and S. Minner, “Optimal day-ahead trading and storage of renewable energies - an approximate dynamic programming approach," Energy Systems, vol. 1, no. 1, pp. 61-77, 2010.

[19] V. Marano, G. Rizzo, and F. A. Tiano, "Application of dynamic programming to the optimal management of a hybrid power plant with wind turbines, photovoltaic panels and compressed air energy storage," Applied Energy, vol. 97, pp. 849-859, 2012.

[20] A. Sinha and P. Chaporkar, "Optimal power allocation for a renewable energy source," in Proceedings of National Conference on Communications, 2012.

[21] Y. P. Cai, G. H. Huang, Z. F. Yang, Q. G. Lin, and Q. Tan, "Community-scale renewable energy systems planning under uncertainty-an interval chance-constrained programming approach," Renewable and Sustainable Energy Reviews, vol. 13, no. 4, pp. 721-735, 2009. 
[22] S. Tomasin and T. Erseghe, "Constrained optimization of local sources generation in smart grids by SDP approximation," in Proceedings of IEEE International Symposium on Power Line Communications and Its Applications (ISPLC '11), pp. 187-192, April 2011.

[23] M. R. Garey and D. S. Johnson, Computers and Intractability: A Guide to the Theory of NP-Completeness, A Series of Books in the Mathematical Sciences, W. H. Freeman, San Francisco, Calif, USA, 1979.

[24] R. Baños, F. Manzano-Agugliaro, F. G. Montoya, C. Gil, A. Alcayde, and J. Gómez, "Optimization methods applied to renewable and sustainable energy: a review," Renewable and Sustainable Energy Reviews, vol. 15, no. 4, pp. 1753-1766, 2011.

[25] K. Chau, "A review on the integration of artificial intelligence into coastal modeling," Journal of Environmental Management, vol. 80, no. 1, pp. 47-57, 2006.

[26] J. Han, M. Kamber, and J. Pei, Data Mining: Concepts and Techniques, Morgan Kaufmann, Waltham, Mass, USA, 3rd edition, 2012.

[27] M. Li, S. C. Lim, and W. Zhao, "Cauchy-Matern model of sea surface wind speed at the Lake Worth, Florida," Mathematical Problems in Engineering, vol. 2012, Article ID 843676, 10 pages, 2012.

[28] M. Li, Y. Q. Chen, J.-Y. Li, and W. Zhao, "Hölder scales of sea level," Mathematical Problems in Engineering, vol. 2012, Article ID 863707, 22 pages, 2012.

[29] J. Makhoul, "Linear prediction: a tutorial review," Proceedings of the IEEE, vol. 63, no. 4, pp. 561-580, 1975.

[30] B. S. Atal, "The history of linear prediction," IEEE Signal Processing Magazine, vol. 23, no. 2, pp. 154-161, 2006.

[31] M. Li, W. Zhao, and B. Chen, "Heavy-tailed prediction error: a difficulty in predicting biomedical signals of $1 / f$ noise type," Computational and Mathematical Methods in Medicine, vol. 2012, Article ID 291510, 5 pages, 2012.

[32] M. Kawashima, "Artificial neural network backpropagation model with three-phase annealing developed for the building energy predictor shootout," ASHRAE Transactions, vol. 100, no. 2, pp. 1096-1103, 1994.

[33] S. M. Islam, S. M. Al-Alawi, and K. A. Ellithy, "Forecasting monthly electric load and energy for a fast growing utility using an artificial neural network," Electric Power Systems Research, vol. 34, no. 1, pp. 1-9, 1995.

[34] A. Al-Shehri, "Artificial neural network for forecasting residential electrical energy," International Journal of Energy Research, vol. 23, no. 8, pp. 649-659, 1999.

[35] A. Azadeh, S. F. Ghaderi, and S. Sohrabkhani, "A simulatedbased neural network algorithm for forecasting electrical energy consumption in Iran," Energy Policy, vol. 36, no. 7, pp. 2637-2644, 2008.

[36] G. J. Tsekouras, N. D. Hatziargyriou, and E. N. Dialynas, "An optimized adaptive neural network for annual midterm energy forecasting," IEEE Transactions on Power Systems, vol. 21, no. 1, pp. 385-391, 2006.

[37] A. Sözen, M. A. Akçayol, and E. Arcaklioğlu, "Forecasting net energy consumption using artificial neural network," Energy Sources, Part B, vol. 1, no. 2, pp. 147-155, 2006.

[38] A. Azadeh, S. F. Ghaderi, and S. Sohrabkhani, "Annual electricity consumption forecasting by neural network in high energy consuming industrial sectors," Energy Conversion and Management, vol. 49, no. 8, pp. 2272-2278, 2008.
[39] A. H. Neto and F. A. S. Fiorelli, "Comparison between detailed model simulation and artificial neural network for forecasting building energy consumption," Energy and Buildings, vol. 40, no. 12, pp. 2169-2176, 2008.

[40] R. Yokoyama, T. Wakui, and R. Satake, "Prediction of energy demands using neural network with model identification by global optimization," Energy Conversion and Management, vol. 50, no. 2, pp. 319-327, 2009.

[41] Z. W. Geem and W. E. Roper, "Energy demand estimation of South Korea using artificial neural network," Energy Policy, vol. 37, no. 10, pp. 4049-4054, 2009.

[42] K. Ermis, A. Midilli, I. Dincer, and M. A. Rosen, "Artificial neural network analysis of world green energy use," Energy Policy, vol. 35, no. 3, pp. 1731-1743, 2007.

[43] J. L. Bosch, G. López, and F. J. Batlles, "Daily solar irradiation estimation over a mountainous area using artificial neural networks," Renewable Energy, vol. 33, no. 7, pp. 1622-1628, 2008.

[44] J. Cao and X. Lin, "Application of the diagonal recurrent wavelet neural network to solar irradiation forecast assisted with fuzzy technique," Engineering Applications of Artificial Intelligence, vol. 21, no. 8, pp. 1255-1263, 2008.

[45] P. L. Zervas, H. Sarimveis, J. A. Palyvos, and N. C. G. Markatos, "Prediction of daily global solar irradiance on horizontal surfaces based on neural-network techniques," Renewable Energy, vol. 33, no. 8, pp. 1796-1803, 2008.

[46] W. Huang, C. Murray, N. Kraus, and J. Rosati, "Development of a regional neural network for coastal water level predictions," Ocean Engineering, vol. 30, no. 17, pp. 2275-2295, 2003.

[47] M. H. Kazeminezhad, A. Etemad-Shahidi, and S. J. Mousavi, "Application of fuzzy inference system in the prediction of wave parameters," Ocean Engineering, vol. 32, no. 14-15, pp. 1709-1725, 2005.

[48] A. Mellit, S. A. Kalogirou, L. Hontoria, and S. Shaari, "Artificial intelligence techniques for sizing photovoltaic systems: a review," Renewable and Sustainable Energy Reviews, vol. 13, no. 2, pp. 406-419, 2009.

[49] A. Mellit, M. Benghanem, A. H. Arab, and A. Guessoum, "Modelling of sizing the photovoltaic system parameters using artificial neural network," in Proceedings of IEEE Conference on Control Applications, vol. 1, pp. 353-357, June 2003.

[50] A. Mellit, M. Benghanem, A. H. Arab, and A. Guessoum, "An adaptive artificial neural network model for sizing stand-alone photovoltaic systems: application for isolated sites in Algeria," Renewable Energy, vol. 30, no. 10, pp. 1501-1524, 2005.

[51] L. Hontoria, J. Aguilera, and P. Zufiria, "A new approach for sizing stand alone photovoltaic systems based in neural networks," Solar Energy, vol. 78, no. 2, pp. 313-319, 2005.

[52] A. Mellit, M. Benghanem, A. Hadj Arab, and A. Guessoum, "Identification and modeling of the optimal sizing combination of stand-alone photovoltaic systems using the radial basis function networks," in Proceedings of the World Renewable Energy Congress VIII (WREC '04), Denver, Colo, USA, 2004.

[53] J. H. Holland, Adaptation in Natural and Artificial Systems, University of Michigan Press, Ann Arbor, Mich, USA, 1975.

[54] D. B. Fogel, "Introduction to simulated evolutionary optimization," IEEE Transactions on Neural Networks, vol. 5, no. 1, pp. 3-14, 1994.

[55] I. Rechenberg, Evolutions Strategies: Optimierung Technischer Systemenach Prinzipien der Biologischen Evolution, Frommberg-Holzboog, Stuttgart, Germany, 1973. 
[56] R. Storn and K. Price, "Differential evolution-a simple and efficient heuristic for global optimization over continuous spaces," Journal of Global Optimization, vol. 11, no. 4, pp. 341359, 1997.

[57] D. Simon, "Biogeography-based optimization," IEEE Transactions on Evolutionary Computation, vol. 12, no. 6, pp. 702-713, 2008.

[58] K. Miettinen, Nonlinear Multiobjective Optimization, International Series in Operations Research \& Management Science, 12, Kluwer Academic Publishers, Boston, Mass, USA, 1999.

[59] Q. S. Li, D. K. Liu, J. Q. Fang, and C. M. Tam, "Multi-level optimal design of buildings with active control under winds using genetic algorithms," Journal of Wind Engineering and Industrial Aerodynamics, vol. 86, no. 1, pp. 65-86, 2000.

[60] H. Li, Z. Chen, and H. Polinder, "Optimization of multibrid permanent-magnet wind generator systems," IEEE Transactions on Energy Conversion, vol. 24, no. 1, pp. 82-92, 2009.

[61] S. A. Grady, M. Y. Hussaini, and M. M. Abdullah, "Placement of wind turbines using genetic algorithms," Renewable Energy, vol. 30, no. 2, pp. 259-270, 2005.

[62] A. Emami and P. Noghreh, "New approach on optimization in placement of wind turbines within wind farm by genetic algorithms," Renewable Energy, vol. 35, no. 7, pp. 1559-1564, 2010.

[63] Varun and Siddhartha, "Thermal performance optimization of a flat plate solar air heater using genetic algorithm," Applied Energy, vol. 87, no. 5, pp. 1793-1799, 2010.

[64] M. Zagrouba, A. Sellami, M. Bouaïcha, and M. Ksouri, "Identification of PV solar cells and modules parameters using the genetic algorithms: application to maximum power extraction," Solar Energy, vol. 84, no. 5, pp. 860-866, 2010.

[65] K. Tselepidou and K. L. Katsifarakis, "Optimization of the exploitation system of a low enthalpy geothermal aquifer with zones of different transmissivities and temperatures," Renewable Energy, vol. 35, no. 7, pp. 1408-1413, 2010.

[66] S. H. El-Hefnawi, "Photovoltaic diesel-generator hybrid power system sizing," Renewable Energy, vol. 13, no. 1, pp. 33-40, 1998.

[67] R. Dufo-López and J. L. Bernal-Agustín, "Design and control strategies of PV-diesel systems using genetic algorithms," Solar Energy, vol. 79, no. 1, pp. 33-46, 2005.

[68] E. Koutroulis, D. Kolokotsa, A. Potirakis, and K. Kalaitzakis, "Methodology for optimal sizing of standalone photovoltaic/wind-generator systems using genetic algorithms," Solar Energy, vol. 80, no. 9, pp. 1072-1088, 2006.

[69] R. Dufo-López, J. L. Bernal-Agustín, and J. Contreras, "Optimization of control strategies for stand-alone renewable energy systems with hydrogen storage," Renewable Energy, vol. 32, no. 7, pp. 1102-1126, 2007.

[70] T. Senjyu, D. Hayashi, A. Yona, N. Urasaki, and T. Funabashi, "Optimal configuration of power generating systems in isolated island with renewable energy," Renewable Energy, vol. 32, no. 11, pp. 1917-1933, 2007.

[71] D. Fogel and K. Chellapilla, "Revisiting evolutionary programming," in Applications and Science of Computational Intelligence, Proceedings of SPIE, pp. 2-11, Orlando, Fla, USA, 1998.

[72] T. D. H. Cau and R. J. Kaye, "Multiple distributed energy storage scheduling using constructive evolutionary programming," in Proceedings of the 22nd IEEE International Conference on Power Industry Computer Applications, pp. 402-407, May 2001.

[73] K. F. Fong, V. I. Hanby, and T. T. Chow, "HVAC system optimization for energy management by evolutionary programming," Energy and Buildings, vol. 38, no. 3, pp. 220-231, 2006.
[74] I. F. MacGill, "An evolutionary programming tool for assessing the operational value of distributed energy resources within restructured electricity industries," in Proceedings of the Australasian Universities Power Engineering (AUPEC '07), pp. 1-6, Australasian Universities, December 2007.

[75] S. Chen, Y. Zheng, C. Cattani, and W. Wang, "Modeling of biological intelligence for SCM system optimization," Computational and Mathematical Methods in Medicine, vol. 2012, Article ID 769702, 10 pages, 2012.

[76] Y. C. Chang, "Optimal chiller loading by evolution strategy for saving energy," Energy and Buildings, vol. 39, no. 4, pp. 437-444, 2007.

[77] T. Logenthiran, D. Srinivasan, A. M. Khambadkone, and T. Sundar Raj, "Optimal sizing of distributed energy resources for integrated microgrids using evolutionary strategy," in Proceedings of IEEE Congress on Evolutionary Computation, pp. 1-8, 2012.

[78] M. A. Falcone, H. S. Lopes, and L. dos Santos Coelho, "Supply chain optimisation using evolutionary algorithms," International Journal of Computer Applications in Technology, vol. 31, no. 3-4, pp. 158-167, 2008.

[79] S. Chakraborty, T. Senjyu, A. Yona, A. Y. Saber, and T. Funabashi, "Fuzzy unit commitment strategy integrated with solar energy system using a modified differential evolution approach," in Proceedings of Asia and Pacific Conference \& Exposition on Transmission \& Distribution, pp. 1-4, October 2009.

[80] L. Slimani and T. Bouktir, "Application of differential evolution algorithm to optimal power flow with high wind energy penetration," Acta Electrotehnica, vol. 53, no. 1, pp. 59-68, 2012.

[81] L. dos Santos Coelho, A. D. V. De Almeida, and V. C. Mariani, "Cultural differential evolution approach to optimize the economic dispatch of electrical energy using thermal generators," in Proceedings of the 13th IEEE International Conference on Emerging Technologies and Factory Automation (ETFA '08), pp. 1378-1383, September 2008.

[82] R. Suzuki, F. Kawai, S. Kitagawa et al., "The $\varepsilon$ constrained differential evolution approach for optimal operational planning of energy plants," in Proceedings of IEEE Congress on Evolutionary Computation (CEC '10), July 2010.

[83] H. A. Hejazi, H. R. Mohabati, S. H. Hosseinian, and M. Abedi, "Differential evolution algorithm for security-constrained energy and reserve optimization considering credible contingencies," IEEE Transactions on Power Systems, vol. 26, no. 3, pp. 1145-1155, 2011.

[84] W. S. Lee, Y. T. Chen, and Y. Kao, "Optimal chiller loading by differential evolution algorithm for reducing energy consumption," Energy and Buildings, vol. 43, no. 2-3, pp. 599-604, 2011.

[85] L. Peng, Y. Wang, G. Dai, Y. Chang, and F. Chen, "Optimization of the Earth-Moon low energy transfer with differential evolution based on uniform design," in Proceedings of IEEE Congress on Evolutionary Computation (CEC '10), July 2010.

[86] N. Srinivas and K. Deb, "Multiobjective optimization using nondominated sorting in genetic algorithms," Evolutionary Computing, vol. 2, pp. 221-248, 1994.

[87] K. Deb, A. Pratap, S. Agarwal, and T. Meyarivan, "A fast and elitist multiobjective genetic algorithm: NSGA-II," IEEE Transactions on Evolutionary Computation, vol. 6, no. 2, pp. 182197, 2002.

[88] E. Zitzler and L. Thiele, "Multiobjective evolutionary algorithms: a comparative case study and the strength Pareto 
approach," IEEE Transactions on Evolutionary Computation, vol. 3, no. 4, pp. 257-271, 1999.

[89] E. Zitzler, M. Laumanns, and L. Thiele, "SPEA2: improving the strength Pareto evolutionary algorithm," in Evolutionary Methods for Design, Optimization and Control with Applications to Industrial Problems, K. Giannakoglou, D. Tsahalis, J. Periaux, P. Papailou, and T. Fogarty, Eds., Athens, Greece, 2001.

[90] J. D. Knowles and D. W. Corne, "M-PAES: a memetic algorithm for multiobjective optimization," in Proceedings of the Congress on Evolutionary Computation (CEC '00), vol. 1, pp. 325-332, July 2000.

[91] H. A. Abbass, R. Sarker, and C. Newton, "PDE: a pareto-frontier differential evolution approach for multi-objective optimization problems," in Proceedings of IEEE Congress on Evolutionary Computation, vol. 2, pp. 971-978, May 2001.

[92] R. Angira and B. V. Babu, "Non-dominated sorting differential evolution (NSDE): an extension of differential evolution for multi-objective optimization," in Proceedings of 2 nd Indian International Conference on Artificial Intelligence, 2005.

[93] Y. J. Zheng, Q. Song, and S. Y. Chen, "Multiobjective fireworks optimization for variable-rate fertilization in oil crop production," Applied Soft Computing. In press.

[94] E. Benini and A. Toffolo, "Optimal design of horizontal-axis wind turbines using blade-element theory and evolutionary computation," Journal of Solar Energy Engineering, vol. 124, no. 4, pp. 357-363, 2002.

[95] M. Zhao, Z. Chen, and F. Blaabjerg, "Optimisation of electrical system for offshore wind farms via genetic algorithm," IET Renewable Power Generation, vol. 3, no. 2, pp. 205-216, 2009.

[96] A. Kusiak, Z. Zhang, and M. Li, "Optimization of wind turbine performance with data-driven models," IEEE Transactions on Sustainable Energy, vol. 1, no. 2, pp. 66-76, 2010.

[97] A. Kusiak and Z. Song, "Design of wind farm layout for maximum wind energy capture," Renewable Energy, vol. 35, no. 3, pp. 685-694, 2010.

[98] J. L. Bernal-Agustín, R. Dufo-López, and D. M. Rivas-Ascaso, "Design of isolated hybrid systems minimizing costs and pollutant emissions," Renewable Energy, vol. 31, no. 14, pp. 22272244, 2006.

[99] R. Dufo-López and J. L. Bernal-Agustín, "Multi-objective design of PV-wind-diesel-hydrogen-battery systems," Renewable Energy, vol. 33, no. 12, pp. 2559-2572, 2008.

[100] B. Ould Bilal, V. Sambou, P. A. Ndiaye, C. M. F. Kébé, and M. Ndongo, "Optimal design of a hybrid solar-wind-battery system using the minimization of the annualized cost system and the minimization of the loss of power supply probability (LPSP)," Renewable Energy, vol. 35, no. 10, pp. 2388-2390, 2010.

[101] F. G. Montoya, R. Banos, C. Gil, A. Espin, A. Alcayde, and J. Gomez, "Minimization of voltage deviation and power losses in power networks using Pareto optimization methods," Engineering Applications of Artificial Intelligence, vol. 23, pp. 695-703, 2010.

[102] Y. Thiaux, J. Seigneurbieux, B. Multon, and H. Ben Ahmed, "Load profile impact on the gross energy requirement of standalone photovoltaic systems," Renewable Energy, vol. 35, no. 3, pp. 602-613, 2010.

[103] P. Rao and C. H. Peng, "A research on power dispatch of energy-saving and emission-reduction generation based on the improved differential evolution algorithm," Journal of East China Jiaotong University, vol. 5, pp. 48-52, 2010.
[104] P. Tarasewich and P. R. McMullen, "Swarm intelligence powers in numbers," Communications of the ACM, vol. 45, no. 8, pp. 62-67, 2002.

[105] E. Bonabeau, M. Dorigo, and G. Theraulaz, Swarm Intelligence: From Natural to Artificial Systems, Oxford University Press, New York, NY, USA, 1999.

[106] J. Kennedy and R. Eberhart, "Particle swarm optimization," in Proceedings of the IEEE International Conference on Neural Networks, pp. 1942-1948, Perth, Australia, December 1995.

[107] A. Colorni, M. Dorigo, and V. Maniezzo, "Distributed optimization by ant colonies," in Proceedings of European Conference on Artificial Life, pp. 134-142, Paris, France, 1991.

[108] X. S. Yang, "Engineering optimizations via nature-inspired virtual bee algorithms," in Proceedings of the 1st International Work-Conference on the Interplay Between Natural and Artificial Computation (IWINAC '05), vol. 3562 of Lecture Notes in Computer Science, pp. 317-323, Springer, Las Palmas, Spain, June 2005.

[109] D. Karaboga and B. Basturk, "A powerful and efficient algorithm for numerical function optimization: artificial bee colony (ABC) algorithm," Journal of Global Optimization, vol. 39, no. 3, pp. 459-471, 2007.

[110] J. D. Farmer, N. H. Packard, and A. S. Perelson, "The immune system, adaptation, and machine learning," Physica D, vol. 22, no. 1-3, pp. 187-204, 1986.

[111] J. Kennedy, "Bare bones particle swarms," in Proceedings of IEEE Swarm Intelligence Symposium, pp. 120-127, IEEE Press, 2003.

[112] M. R. AlRashidi and K. M. EL-Naggar, "Long term electric load forecasting based on particle swarm optimization," Applied Energy, vol. 87, no. 1, pp. 320-326, 2010.

[113] T. Niknam and B. B. Firouzi, "A practical algorithm for distribution state estimation including renewable energy sources," Renewable Energy, vol. 34, no. 11, pp. 2309-2316, 2009.

[114] N. Amjady and H. R. Soleymanpour, "Daily Hydrothermal Generation Scheduling by a new Modified Adaptive Particle Swarm Optimization technique," Electric Power Systems Research, vol. 80, no. 6, pp. 723-732, 2010.

[115] Z. H. Zhan, J. Zhang, Y. Li, and H. S. H. Chung, "Adaptive particle swarm optimization," IEEE Transactions on Systems, Man, and Cybernetics, Part B, vol. 39, no. 6, pp. 1362-1381, 2009.

[116] Y.-J. Zheng, H.-F. Ling, and Q. Guan, "Adaptive parameters for a modified comprehensive learning particle swarm optimizer," Mathematical Problems in Engineering, vol. 2013, 11 pages, 2013.

[117] T. Y. Lee, "Short term hydroelectric power system scheduling with wind turbine generators using the multi-pass iteration particle swarm optimization approach," Energy Conversion and Management, vol. 49, no. 4, pp. 751-760, 2008.

[118] C. Kongnam and S. Nuchprayoon, "A particle swarm optimization for wind energy control problem," Renewable Energy, vol. 35, no. 11, pp. 2431-2438, 2010.

[119] S. Khanmohammadi, M. Amiri, and M. T. Haque, "A new threestage method for solving unit commitment problem," Energy, vol. 35, no. 7, pp. 3072-3080, 2010.

[120] P. R. López, F. Jurado, N. Ruiz-Reyes, S. García Galán, and M. Gómez, "Particle swarm optimization for biomass-fuelled systems with technical constraints," Engineering Applications of Artificial Intelligence, vol. 21, no. 8, pp. 1389-1396, 2008.

[121] P. R. Lopez, S. G. Galan, N. Ruiz-Reyes, and F. Jurado, "A method for particle swarm optimization and its application in location of biomass power plants," International Journal of Green Energy, vol. 5, no. 3, pp. 199-211, 2008. 
[122] T. Y. Lee and C. L. Chen, "Wind-photovoltaic capacity coordination for a time-of-use rate industrial user," IET Renewable Power Generation, vol. 3, no. 2, pp. 152-167, 2009.

[123] A. K. Kaviani, G. H. Riahy, and S. M. Kouhsari, "Optimal design of a reliable hydrogen-based stand-alone wind/PV generating system, considering component outages," Renewable Energy, vol. 34, no. 11, pp. 2380-2390, 2009.

[124] A. Kornelakis and E. Koutroulis, "Methodology for the design optimisation and the economic analysis of grid-connected photovoltaic systems," IET Renewable Power Generation, vol. 3, no. 4, pp. 476-492, 2009.

[125] A. Kornelakis and Y. Marinakis, "Contribution for optimal sizing of grid-connected PV-systems using PSO," Renewable Energy, vol. 35, no. 6, pp. 1333-1341, 2010.

[126] S. M. Hakimi and S. M. Moghaddas-Tafreshi, "Optimal sizing of a stand-alone hybrid power system via particle swarm optimization for Kahnouj area in south-east of Iran," Renewable Energy, vol. 34, no. 7, pp. 1855-1862, 2009.

[127] A. Mahor, V. Prasad, and S. Rangnekar, "Economic dispatch using particle swarm optimization: a review," Renewable and Sustainable Energy Reviews, vol. 13, no. 8, pp. 2134-2141, 2009.

[128] Z. L. Gaing, "Particle swarm optimization to solving the economic dispatch considering the generator constraints," IEEE Transactions on Power Systems, vol. 18, no. 3, pp. 1187-1195, 2003.

[129] D. N. Jeyakumar, T. Jayabarathi, and T. Raghunathan, "Particle swarm optimization for various types of economic dispatch problems," International Journal of Electrical Power \& Energy Systems, vol. 28, no. 1, pp. 36-42, 2006.

[130] L. Wang and C. Singh, "Reserve-constrained multiarea environmental/economic dispatch based on particle swarm optimization with local search," Engineering Applications of Artificial Intelligence, vol. 22, no. 2, pp. 298-307, 2009.

[131] K. K. Mandal, M. Basu, and N. Chakraborty, "Particle swarm optimization technique based short-term hydrothermal scheduling," Applied Soft Computing Journal, vol. 8, no. 4, pp. 1392-1399, 2008.

[132] R. Chakrabarti, P. K. Chattopadhyay, M. Basu, and C. K. Panigrahi, "Particle swarm optimization technique for dynamic economic dispatch," Journal of the Institution of Engineers, vol. 87, pp. 48-54, 2006.

[133] J. B. Park, Y. W. Jeong, H. H. Kim, and J. R. Shin, "An improved particle swarm optimization for economic load dispatch with valve point effect," International Journal of Innovations in Energy Systems and Power, vol. 1, no. 1, 2006.

[134] L. dos Santos Coelho and V. C. Mariani, "Economic dispatch optimization using hybrid chaotic particle swarm optimizer," in Proceedings of IEEE International Conference on Systems, Man, and Cybernetics (SMC '07), pp. 1963-1968, October 2007.

[135] J. Cai, X. Ma, L. Li, and P. Haipeng, "Chaotic particle swarm optimization for economic dispatch considering the generator constraints," Energy Conversion and Management, vol. 48, no. 2, pp. 645-653, 2007.

[136] A. I. S. Kumar, K. Dhanushkodi, J. J. Kumar, and C. K. C. Paul, "Particle swarm optimization solution to emission and economic dispatch problem," in Proceedings of IEEE Confernce on Covergent Technologies for the Asia-Pacific Region (TENCON '03), vol. 1, pp. 435-439, October 2003.

[137] B. Zhao, C. Guo, and Y. Cao, "Dynamic economic dispatch in electricity market using particle swarm optimization algorithm," in Proceedings of 5th World Congress on Intelligent Control and Automation (WCICA '04), pp. 5050-5054, June 2004.
[138] M. A. Abido, "Multiobjective particle swarm for environmental/economic dispatch problem," in Proceedings of the 8th International Power Engineering Conference (IPEC '07), pp. 1385-1390, December 2007.

[139] M. A. Alrashidi and M. E. Hawary, "Impact of loading conditions on the emission economic dispatch," in Proceedings of World Academy of Science and Engineering and Technology, pp. 148-151, 2008.

[140] Z. Li, X. P. Chang, and J. H. Qin, "Application of ant colony algorithms to optimization design of solar energy dynamic power system in space station," Proceedings of the Chinese Society of Electrical Engineering, vol. 25, pp. 294-298, 2005.

[141] D. Xu, L. Kang, and B. Cao, "Graph-based ant system for optimal sizing of standalone hybrid wind/PV power systems," in Computational Intelligence, vol. 4114 of Lecture Notes in Computer Science, pp. 1136-1146, Springer, 2006.

[142] W. K. Foong, H. R. Maier, and A. R. Simpson, "Power plant maintenance scheduling using ant colony optimization: an improved formulation," Engineering Optimization, vol. 40, no. 4, pp. 309-329, 2008.

[143] L. Warner and U. Vogel, "Optimization of energy supply networks using ant colony optimization," in Proceedings of 22th International Conference on Informatics for Environmental Protection, pp. 327-334, 2008.

[144] P. C. See, V. C. Tai, and M. Molinas, "Ant colony optimization applied to control of ocean wave energy converters," Energy Procedia, vol. 20, pp. 148-155, 2012.

[145] M. D. Toksari, "Estimating the net electricity energy generation and demand using the ant colony optimization approach: case of Turkey," Energy Policy, vol. 37, no. 3, pp. 1181-1187, 2009.

[146] O. Baskan, S. Haldenbilen, H. Ceylan, and H. Ceylan, "Estimating transport energy demand using ant colony optimization," Energy Sources, Part B, vol. 7, no. 2, pp. 188-199, 2012.

[147] A. Afshar, O. Bozorg Haddad, M. A. Mariño, and B. J. Adams, "Honey-bee mating optimization (HBMO) algorithm for optimal reservoir operation," Journal of the Franklin Institute, vol. 344, no. 5, pp. 452-462, 2007.

[148] T. Niknam, S. I. Taheri, J. Aghaei, S. Tabatabaei, and M. Nayeripour, "A modified honey bee mating optimization algorithm for multiobjective placement of renewable energy resources," Applied Energy, vol. 88, no. 12, pp. 4817-4830, 2011.

[149] T. Niknam, H. D. Mojarrad, H. Z. Meymand, and B. B. Firouzi, "A new honey bee mating optimization algorithm for nonsmooth economic dispatch," Energy, vol. 36, no. 2, pp. 896-908, 2011.

[150] F. S. Abu-Mouti and M. E. El-Hawary, "Optimal dynamic economic dispatch including renewable energy source using artificial bee colony algorithm," in Proceedings of IEEE Systems Conference, 2012.

[151] D. Vera, J. Carabias, F. Jurado, and N. Ruiz-Reyes, "A Honey Bee Foraging approach for optimal location of a biomass power plant," Applied Energy, vol. 87, no. 7, pp. 2119-2127, 2010.

[152] W. C. Hong, "Electric load forecasting by seasonal recurrent SVR (support vector regression) with chaotic artificial bee colony algorithm," Energy, vol. 36, no. 9, pp. 5568-5578, 2011.

[153] T. K. Abdul Rahman, Z. M. Yasin, and W. N. W. Abdullah, "Artificial-immune-based for solving economic dispatch in power system," in Proceedings of National Power and Energy Conference (PECon '04), pp. 31-35, November 2004.

[154] L. D. S. Coelho and V. C. Mariani, "Chaotic artificial immune approach applied to economic dispatch of electric energy using 
thermal units," Chaos, Solitons \& Fractals, vol. 40, no. 5, pp. 2376-2383, 2009.

[155] P. Arsalani and M. Seddighizadeh, "Minimizing the loss of energy in transmission systems with capacitor placement using an immune algorithm and fuzzy logic," in Proceedings of 2 nd Conference on Energy Management and Conservation, 2012.

[156] A. Mellit and S. A. Kalogirou, "Application of neural networks and genetic algorithms for predicting the optimal sizing coefficient of photovoltaic supply (PVS) systems," in Proceedings of the World Renewable Energy Congress IX and Exhibition, 2006.

[157] A. Mellit, "ANFIS-based genetic algorithm for predicting the optimal sizing coefficient of photovoltaic supply (PVS) systems," in Proceedings of 3rd International Conference on Thermal Engineering: Theory and Applications, pp. 96-102, 2007.

[158] Y. P. Chang and C. N. Ko, "A PSO method with nonlinear time-varying evolution based on neural network for design of optimal harmonic filters," Expert Systems with Applications, vol. 36, no. 3, pp. 6809-6816, 2009.

[159] A. Li, L. Wang, J. Li, and C. Ji, "Application of immune algorithm-based particle swarm optimization for optimized load distribution among cascade hydropower stations," Computers and Mathematics with Applications, vol. 57, no. 11-12, pp. 1785-1791, 2009.

[160] Z. X. Yang, X. F. Yue, and L. Wang, "Study on the energy consumption optimization in a central air-conditioning system based on bee evolutionary genetic algorithm method," Building Science, vol. 27, no. 6, pp. 78-82, 2011.

[161] M. S. Kiran, E. Özceylan, M. Gündüz, and T. Paksoy, "A novel hybrid approach based on particle swarm optimization and ant colony algorithm to forecast energy demand of Turkey," Energy Conversion and Management, vol. 53, no. 1, pp. 75-83, 2012.

[162] A. Ghanbari, M. Kazemi, F. Mehmanpazir, and M. M. Nakhostin, "A cooperative ant colony optimization-genetic algorithm approach for construction of energy demand forecasting knowledge-based expert systems," Knowledge-Based Systems, vol. 39, pp. 194-206, 2013.

[163] B. Tudu, S. Majumder, K. K. Mandal, and N. Chakraborty, "Comparative performance study of genetic algorithm and particle swarm optimization applied on off-grid renewable hybrid energy system," in Swarm, Evolutionary, and Memetic Computing, vol. 7076 of Lecture Notes in Computer Science, pp. 151-158, Springer, 2011.

[164] M. Carlini and S. Castellucci, "Modelling and simulation for energy production parametric dependence in greenhouses," Mathematical Problems in Engineering, vol. 2010, Article ID 590943, 28 pages, 2010.

[165] M. Carlini, S. Castellucci, M. Guerrieri, and T. Honorati, "Stability and control for energy production parametric dependence," Mathematical Problems in Engineering, vol. 2010, Article ID 842380, 21 pages, 2010.

[166] M. Fadaee and A. M. Radzi, "Multi-objective optimization of a stand-alone hybrid renewable energy system by using evolutionary algorithms: a review," Renewable and Sustainable Energy Reviews, vol. 16, no. 5, pp. 3364-3369, 2012.

[167] J. Gruska, Quantum Computing, Advanced Topics in Computer Science Series, McGraw-Hill, New York, NY, USA, 1999.

[168] G. Păun, G. Rozenberg, and A. Salomaa, DNA Computing: New Computing Paradigms, Texts in Theoretical Computer Science. An EATCS Series, Springer, Berlin, Germany, 1998.

[169] M. Joyeux, S. Buyukdagli, and M. Sanrey, "1/f fluctuations of DNA temperature at thermal denaturation," Physical Review E, vol. 75, no. 6, Article ID 061914, 9 pages, 2007.
[170] A. Castro, M. A. L. Marques, D. Varsano, F. Sottile, and A. Rubio, "The challenge of predicting optical properties of biomolecules: what can we learn from time-dependent density-functional theory?" Comptes Rendus Physique, vol. 10, no. 6, pp. 469-490, 2009.

[171] C. Cattani, E. Laserra, and I. Bochicchio, "Simplicial approach to fractal structures," Mathematical Problems in Engineering, vol. 2012, Article ID 958101, 21 pages, 2012.

[172] C. Cattani, "On the existence of wavelet symmetries in archaea DNA," Computational and Mathematical Methods in Medicine, Article ID 673934, 21 pages, 2012.

[173] G. Zhang, "Quantum-inspired evolutionary algorithms: a survey and empirical study," Journal of Heuristics, vol. 17, no. 3, pp. 303-351, 2011.

[174] E. G. Bakhoum and C. Toma, "Dynamical aspects of macroscopic and quantum transitions due to coherence function and time series events," Mathematical Problems in Engineering, vol. 2010, Article ID 428903, 13 pages, 2010.

[175] E. G. Bakhoum and C. Toma, "Mathematical transform of traveling-wave equations and phase aspects of quantum interaction," Mathematical Problems in Engineering, vol. 2010, Article ID 695208, 15 pages, 2010. 


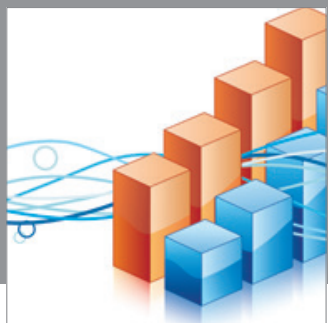

Advances in

Operations Research

mansans

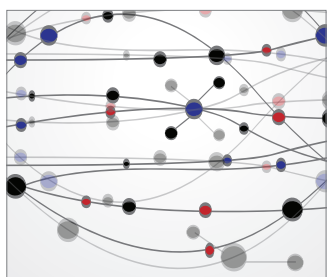

The Scientific World Journal
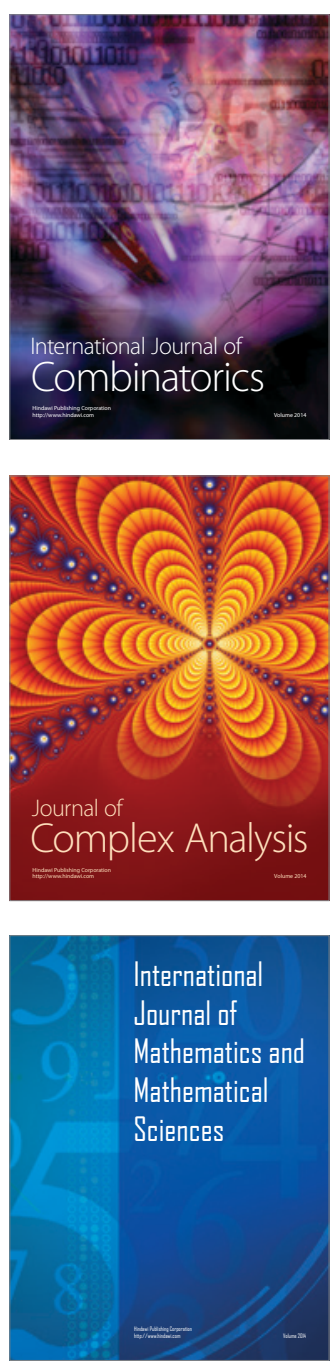
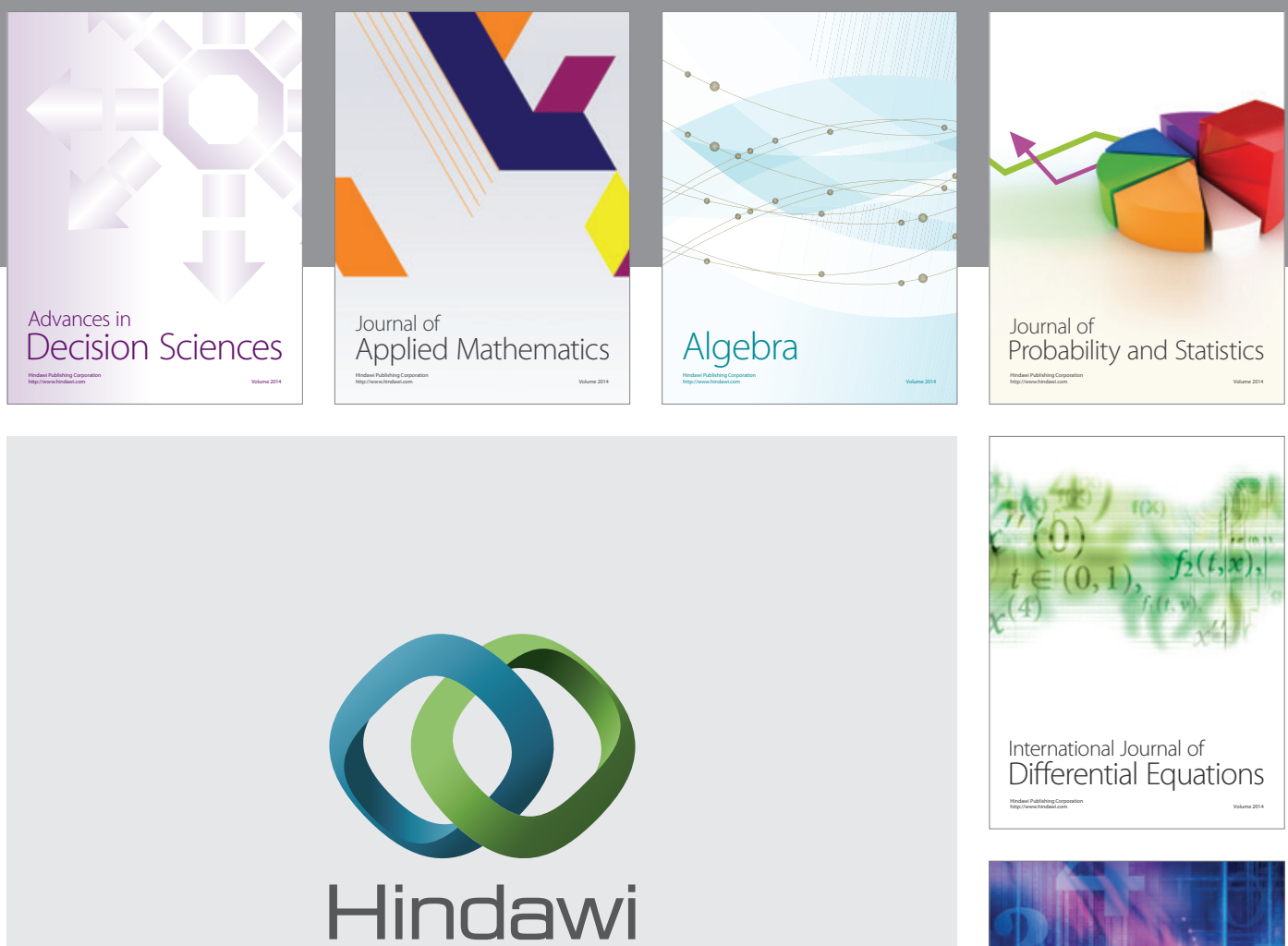

Submit your manuscripts at http://www.hindawi.com
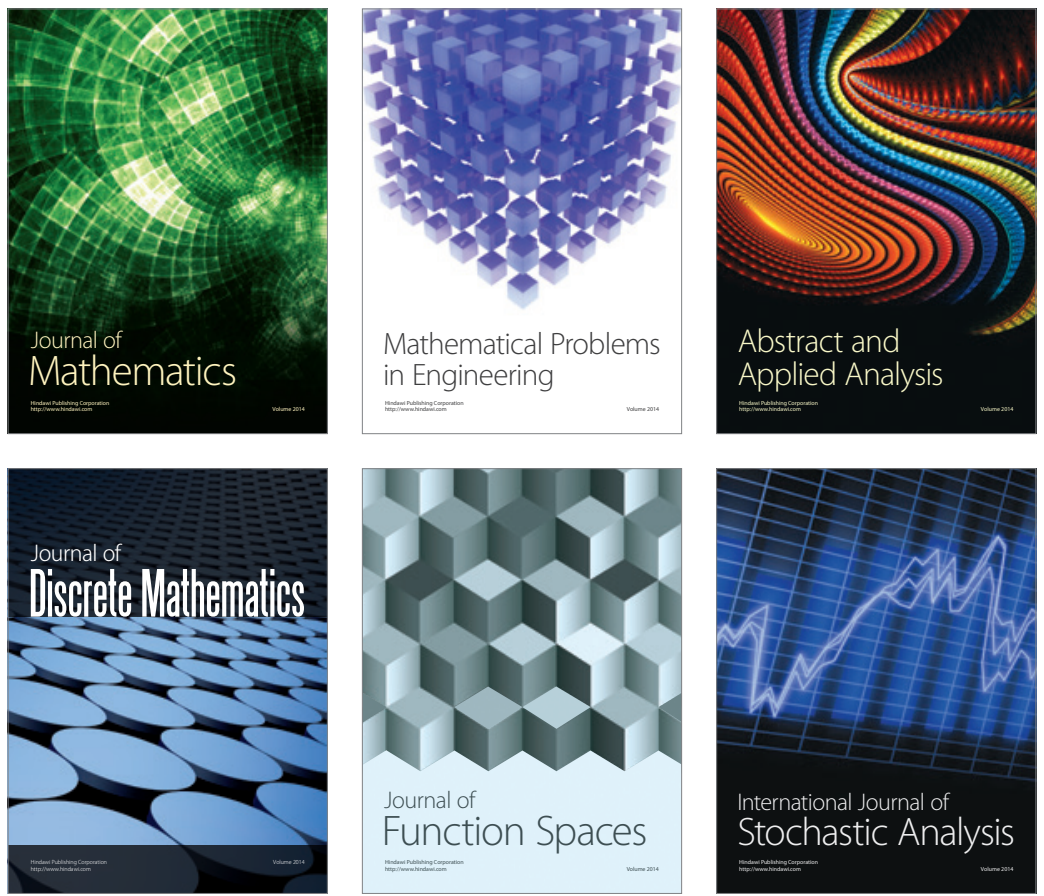

Journal of

Function Spaces

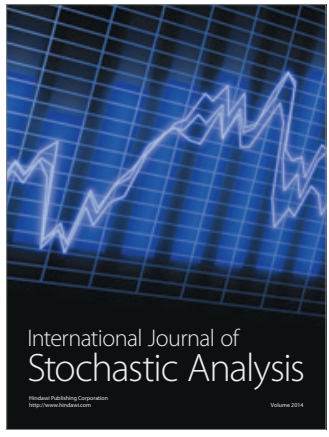

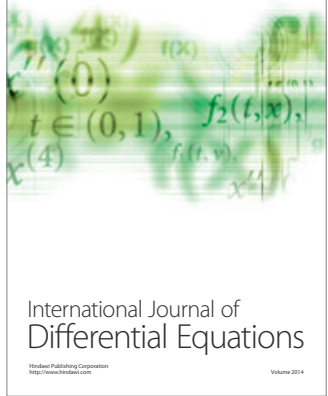
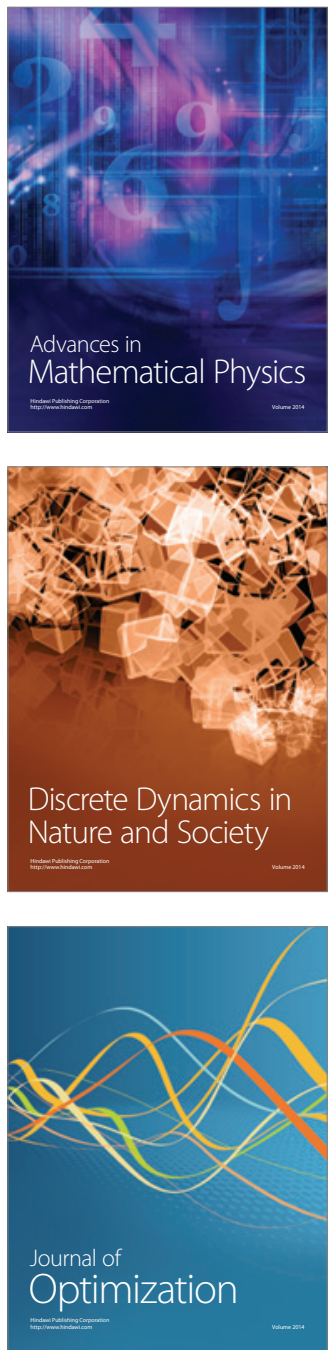